\title{
A Meta-analysis of the Unified Theory of Acceptance and Use of Technology (UTAUT)
}

\author{
Yogesh K. Dwivedi ${ }^{1}$, Nripendra P. Rana ${ }^{1}$, Hsin Chen ${ }^{2}$, and Michael D. Williams ${ }^{1}$ \\ ${ }^{1}$ School of Business \& Economics, Swansea University, Swansea, UK \\ \{ykdwivedi, nrananp\}@gmail.com, M.D.Williams@swansea.ac.uk \\ ${ }^{2}$ Business Systems Department, University of Bedfordshire, UK \\ hsin.chen@beds.ac.uk
}

\begin{abstract}
The originating article of the Unified Theory of Acceptance and Use of Technology (UTAUT) has been cited by a large number of studies. However, a detailed examination of such citations revealed that only small proportion (43 articles) of these citations actually utilized the theory or its constructs in their empirical research for examining IS/IT related issues. In order to examine whether the theory is performing consistently well across various studies, this research aims to undertake a statistical meta-analysis of findings reported in 43 published studies that have actually utilized UTAUT or its constructs in their empirical research. Findings reveal the underperformance of theory in subsequent studies in comparison to the performance of UTAUT reported in the originating article. The limitations experienced while conducting the metaanalysis, recommendations, and the future scope for the further research in this area have also been briefly explained in concluding section.
\end{abstract}

Keywords: Adoption, Diffusion, UTAUT, TAM, Meta-analysis, Information Systems.

\section{Introduction}

UTAUT was proposed as a theoretical advancement over existing theories used to examine adoption and diffusion related research. Venkatesh et al. (2003) reviewed, mapped and integrated constructs from following eight theories and models: theory of reasoned action (TRA), technology acceptance model (TAM), motivational model $(\mathrm{MM})$, theory of planned behavior (TPB), a combined theory of planned behavior/technology acceptance model (C-TPB-TAM), model of PC utilization (MPCU), innovation diffusion theory (IDT), and social cognitive theory (SCT). By doing so the authors aimed to develop a unified view by eliminating redundancy and repetitions as several constructs in these theories were common.

Like its majority of predecessors' theories and models in the area of adoption and diffusion of IT/IS, UTAUT facilitates in examining user's intentions to use an information system and consequent usage behavior. The variance in intentions can be explained by measuring effect of four key independent constructs, namely, performance expectancy (PE), effort expectancy (EE), social influence (SI), and facilitating 
conditions (FC) as direct determinants of usage intention and behavior (Venkatesh et al. 2003). The effect of independent variables on dependent variables is moderated by following four moderating variables: gender, age, experience, and voluntariness of use (Venkatesh et al. 2003).

Two of its constructs are similar to TAM constructs: PE can be mapped to perceived usefulness (PU) whereas EE can be mapped to perceived ease of use (PEOU). The remaining two constructs (SI and FC) are from TPB. Due to the similarity (in terms of constructs and relationships) of UTAUT with TAM and TPB, the current and future adoption and diffusion studies might be favouring use of UTAUT. This is particularly more likely as many scholars in the recent past have criticized over exploitation of TAM which ultimately affecting development of alternative theories and models in this area. However, it is difficult to demonstrate that if UTAUT is replacing TAM in empirical studies as there is no review of previous empirical studies that have utilized UTAUT. Also, there is no study that has surveyed or reviewed performance of UTAUT subsequently - so, there is a lack of information regarding reliability and consistency of performance of this theory in different situations.

Many literature reviews and meta-analyses have been conducted on UTAUT's popular precursor theories and models such as TAM and TPB. For example, use of TAM by a large number of studies caught researchers' attention to analyze trends, patterns of use, and the actual performance of the model through systematic review and meta-analysis technique. The successful efforts towards the systematic review were performed by Lee et al. (2003), and Legris et al. (2003), whereas, the metaanalysis for measuring the performance of TAM was carried out by Deng et al. (2005), King and He (2006), and Ma and Liu (2004). The similar meta-analytic approach was also performed for TPB, and TRA by other previous studies (Hausenblas et al. 1997; Sheeran and Taylor 1999).

A large citation counts for UTAUT's originating article, its use in many empirical studies, an inconsistent performance of the theory, and a lack of reviews and metaanalysis related to it necessitate determining the past and current trends of its use by conducting systematic reviews and meta-analysis of articles that have either cited or utilized it as theoretical basis in their empirical research. Considering above discussions, this study aims to conduct a review and meta-analysis of articles that have cited the originating article (i.e. Venkatesh et al. 2003) and have utilized UTAUT (or its constructs) for undertaking empirical research on adoption and diffusion of IT/IS. According to King and $\mathrm{He}$ (2006, p. 741) "Meta-analysis allows various results to be combined, taking account of the relative sample and effect sizes, thereby allowing both insignificant and significant effects to be analyzed. The overall result is then undoubtedly more accurate and more credible because of the overarching span of the analysis." This outlines contribution of this paper by conducting meta-analysis which might present more accurate and credible performance of the UTAUT theory.

The remaining paper is organized as follows: The next section will provide an overview of the research method utilized. The findings will then be presented and discussed in subsequent sections. The last section of this paper will outline conclusions, limitations and future research directions. 


\section{Research Method}

As the aim of this research is to analyze and synthesize existing findings on use of the UTAUT theory, a combination of profiling review and meta-analysis methods (Deng et al. 2005; King and He 2006; Lee et al. 2003; Legris et al. 2003; Ma and Liu 2004) was considered as the most appropriate one for this purpose. This research utilized data collected from studies that cited UTAUT's originating article (Venkatesh et al. 2003). These citations were identified by employing Web of Science ${ }^{@}$ database. The demographic data (such as year of publications, and source of publications) related to all cited studies were first collected from Web of Science ${ }^{@}$ database. The citations for fully available articles were downloaded for the purpose of extracting further details from the cited articles.

There were total of 870 studies that cited UTAUT, out of which 450 studies were available to be downloaded as full articles. A detailed examination of 450 available studies led to identify 43 studies that used UTAUT (or its constructs) in their empirical studies. The remaining 407 studies just cited the originating article on UTAUT (Venkatesh et al. 2003) and did make full or partial use of the theory in their empirical research. In order to observe modifications, adaptations and integration of external variables with UTAUT by adopting an approach from the research of Legris et al. (2003), this study also analyzed 43 studies to identify the external variables, and external theories they used along with UTAUT.

A further and more detailed analysis of 43 studies (that have used UTAUT) was conducted which revealed that only 27 studies used the quantitative research method (similar to the originating article) and therefore subjected to the meta-analysis. The remaining 16 studies used UTAUT with some different research methods (for example qualitative or other statistical measurement technique) and hence was not considered for meta-analysis. Although 27 studies seem relatively fewer in counts, it was considered adequate in number for conducting the meta-analysis. A similar number of studies were also utilized in previous meta-analyses research (Deng et al. 2005; Legris et al. 2003; Ma and Liu 2004). For example, Legris et al. (2003) successfully conducted meta-analysis on TAM by extracting statistical data from three studies. Ma and Liu (2004) employed data from 26 empirical papers and Deng et al. (2005) collected data from 21 studies. Since these studies are published in respected peer reviewed journal, we considered 27 studies as an appropriate number for this research.

Adopting approach from previous meta-analysis studies (Deng et al. 2005; King and He 2006; Legris et al. 2003; Ma and Liu 2004), the following types of data were collected from 27 studies for the purpose of meta-analysis: reliability of the constructs (Chronbach's $\alpha$ ), sample size, correlation coefficient, and overall variance explained (or adjusted R2).

Meta-analysis is a statistical method by which information from individual studies is assimilated (Field 2001). Aforementioned summary data from each study applied to calculate an effect size for the study. An effect size is a number that exhibits the extent of the affiliation between two variables. The p-value is often used as a surrogate for the effect size, with a considerable p-value taken to entail a significant effect and a nonsignificant p-value taken to imply a marginal effect (Borenstein cited in Cooper et al. 2009). Once the mean effect size has been computed, it can be articulated in terms of standard normal deviations (a Z score) by dividing it by the standard error of the mean. 
A significance value (i.e. the probability, $\mathrm{p}$, of obtaining a $\mathrm{Z}$ score of such magnitude by chance) can then be calculated. Alternatively, the magnitude of the average effect size can be deduced from the boundaries of a confidence interval constructed around the mean effect size (Field 2001). Meta-analysis is used as a way of trying to establish the true effect sizes (i.e. effect sizes in a population) by combining effect sizes from independent studies. There are two ways to conceptualise this process: fixed effect and random effect models. In reality, the random effect model is probably more realistic than the fixed effect on widely held occasions especially when the findings are not restricted only to those studies included in the meta-analysis but used to make general conclusions about the research domain (Field 2001). Considering the above facts, this study has also made use of random effect model for the meta-analysis.

\section{Findings}

\subsection{Demography of Citations}

\section{Citations by Source}

MIS Quarterly emerged as the leading journal with the largest number of citations $(\mathrm{C}=36)$ followed by Lecture Notes on Computer Science as the second most published outlets with 30 citations, this followed by other leading journals such as: Information \& Management (28 citations), Computer in Human Behavior (27 citations), European Journal of Information Systems (27 citations), and Journal of Computer Information Systems (22 citations); Journal of the American Society for Information Science and Technology (17 Citations), IFIP Conferences (16 Citations), International Journal of Human-Computer Studies (16 Citations), Computers \& Education (14 Citations), Journal of The Association For Information Systems (14 Citations), Information Systems Research (13 Citations), Decision Support Systems (12 Citations), IEEE Transactions on Engineering Management (11 Citations), and Journal of Information Technology (10 Citations).

\section{Citations by Year}

The analysis of citation year indicates that citations of the originating article have constantly increased since 2004 when six studies cited it. Thereafter, 62 citations appeared in the year 2005, 91 in 2006, 141 in 2007, 214 in 2008, and 228 citations in 2009. The trend appears to be ongoing as 128 papers already cited the originating theory at the time of writing this paper in mid-2010. The trend suggests that the originating article has quickly gained acceptance and popularity amongst IS/IT researchers.

\section{Theories, Models and External Variables Used with UTAUT}

The aim of this aspect of our analysis is to identify external variables, external theories, and the relationship of external variables with the independent and dependent constructs of UTAUT for all 43 studies which have used UTAUT.

\section{Use of External Theories}

Table 1 lists the seven out of the 43 UTAUT-based studies that used external theories in their research model analyses. Our analysis reveals that TAM is the most 
frequently used theory alongside UTAUT - being utilized on four occasions, followed by Task Technology Fit (TTF) twice, and one instances each of IDT, and SCT.

Table 1. Summary of External Theories

\begin{tabular}{|l|l|}
\hline Reference & External Theory \\
\hline Aggelidis and Chatzoglou (2009) & TAM, TAM2 \\
\hline Baron et al. (2006) & TAM \\
\hline He et al. (2007) & IDT, TTF \\
\hline Tsai (2009) & SCT \\
\hline van Biljon and Kotze (2008) & TAM \\
\hline van Biljon and Renaud (2008) & TAM \\
\hline Zhou et al. (2010) & TTF \\
\hline $\begin{array}{l}\text { LEGEND: IDT: Innovation Diffusion Theory; SCT: Social Cognitive Theory; TAM: Tech- } \\
\text { nology Acceptance Model; TAM2: Extended TAM; TTF: Task Technology Fit }\end{array}$ \\
\hline
\end{tabular}

\section{Use of External Variables}

The findings from our external variables analysis reveal that only 22 out of 43 studies have used external variables in their investigations. The remaining 21 used only the original constructs of UTAUT. Although age, gender, experience, and voluntariness of use are moderating variables in the original UTAUT (Venkatesh et al. 2003), these moderators are treated as external constructs in some of the studies. Attitude, anxiety, trust, self-efficacy, PEOU, PU, perceived risk, and perceived credibility are some of the most common external variables employed. Studies which did not use external variables indicated that they were applying the original theory without altering it to achieve their objectives. Table 2 lists only those studies which used external variables.

The analysis of relationship amongst UTAUT constructs and external constructs (as listed in Table 2) reveals that attainment value, utility value, trust, attitude, perceived ease of use, perceived usefulness, computer self-efficacy, gender, perceived risk, income, and experience have a significant impact on behavioral intention (BI). However, anxiety, training, age, perceived credibility, and social isolation do not have a significant impact and self-efficacy, subjective norm, and objective norm have mixed influence. Furthermore, trust, belief and credibility have a significant and mixed impact on performance expectancy (PE). Similarly, computer anxiety, computer self-efficacy, resistance to change, and relevance have positive impact while credibility has a nonsignificant impact on effort expectancy (EE). Conversely, social influence (SI) is negatively impacted by credibility. Nevertheless, IT knowledge has a positive impact on facilitating conditions (FC). As far as intention to use (IU) or usage (U) is concerned, it is impacted positively by variables from task-technology fit models, and experience but impacted insignificantly by trust, and internet experience. Apart from these external constructs, income has been shown as a moderating variable on BI. 
Table 2. Summary of External Variables

\begin{tabular}{|c|c|}
\hline Reference & External Variables \\
\hline Abu-Shanab and Pearson (2009) & $\begin{array}{l}\text { Self-Efficacy, Anxiety, Perceived Trust, Perceived } \\
\text { Risk, Personal Innovativeness, Locus of Control }\end{array}$ \\
\hline Aggelidis and Chatzoglou (2009) & $\begin{array}{l}\text { Attitude, Self-efficacy, anxiety, Perceived usefulness, } \\
\text { Ease of use, Training }\end{array}$ \\
\hline Chiu et al. (2010) & $\begin{array}{l}\text { Trust, Past Transactions, Gender, Age, Internet } \\
\text { Experience }\end{array}$ \\
\hline Chiu and Wang (2008) & $\begin{array}{l}\text { Computer Self-Efficacy, Attainment Value, Utility } \\
\text { Value, Intrinsic Value (Playfulness), Social Isolation, } \\
\text { Anxiety, Delay in Responses, Risk of Arbitrary } \\
\text { Learning }\end{array}$ \\
\hline Curtis et al. (2010) & Voluntariness of Use, Anxiety, self-efficacy \\
\hline Dadayan and Ferro (2005) & $\begin{array}{l}\text { Compatibility, Computer Anxiety, Computer Attitude, } \\
\text { Acceptance Motivation, Organizational Facilitation }\end{array}$ \\
\hline He et al. (2007) & $\begin{array}{l}\text { Individual Innovativeness, Compatibility, Task } \\
\text { Technology Fit }\end{array}$ \\
\hline Jong and Wang (2009) & Attitude, Self-efficacy, Anxiety \\
\hline Kijsanayotin et al. (2009) & Voluntariness, Experience, Knowledge \\
\hline Laumer et al. (2010) & Subjective Norm, Objective Norm \\
\hline Lin and Anol (2008) & Online Support Expectancy, Online Social Support \\
\hline Loo et al. (2009) & Perceived Credibility, Anxiety \\
\hline Luo et al. (2010) & $\begin{array}{l}\text { Trust Belief, Perceived Risk, Self-Efficacy, } \\
\text { Disposition to Trust }\end{array}$ \\
\hline Nov and Ye (2009) & $\begin{array}{l}\text { Result Demonstrability, Computer Self-Efficacy, } \\
\text { Computer Anxiety, Resistance to Change, Screen } \\
\text { Design, Relevance, Terminology }\end{array}$ \\
\hline Schaupp et al. (2010) & Optimism Bias, Trust of e-file system, Perceived Risk \\
\hline Shin (2009) & Trust, Self Efficacy, Perceived Security \\
\hline van Biljon and Kotze (2008) & $\begin{array}{l}\text { PEOU, PU, Human Nature Influence, and Cultural } \\
\text { Influence Demographic Factors, Socio-Economic } \\
\text { Factors, and Personal Factors }\end{array}$ \\
\hline van Dijk et al. (2008) & $\begin{array}{l}\text { Age, Gender, Educational Level, Societal position, } \\
\text { Family position, Digital Media Preference, Digital } \\
\text { Media Access, Digital Media Experience, Attitude } \\
\text { towards use, Knowledge of Services }\end{array}$ \\
\hline Ye et al. (2008) & $\begin{array}{l}\text { Computer Self-Efficacy, Risk aversion, Social } \\
\text { influences, Breadth of use, Satisfaction, Relative } \\
\text { Advantage, PEOU, Perceived Security }\end{array}$ \\
\hline YenYuen and Yeow (2009) & $\begin{array}{l}\text { Perceived Credibility, Anxiety, Self-Efficacy, Attitude } \\
\text { towards using IBS }\end{array}$ \\
\hline Yeow et al. (2008) & $\begin{array}{l}\text { Perceived Credibility, Anxiety, Self-Efficacy, Attitude } \\
\text { towards using OBS }\end{array}$ \\
\hline Zhou et al. (2010) & Task Technology Fit \\
\hline
\end{tabular}




\subsection{Meta-analysis}

This section aims to investigate the corresponding relationships between constructs, measure their average reliability, the combined correlations between the constructs and their significance, and the major limitations of the studies. The findings from detailed analyses are presented in the following sub-sections.

\section{Sample Size}

Table 3 illustrates the sample sizes from 27 studies that used UTAUT. Two studies by Duyck et al. (2010) and Laumer et al. (2010) have used more than one representative sample to present and compare cases in different scenarios.

Table 3. Sample Sizes

\begin{tabular}{|l|l|l|l|}
\hline Reference & Sample Size & Reference & Sample Size \\
\hline van Dijk et al. (2008) & 1225 & Nov and Ye (2009) & 271 \\
\hline Kijsanayotin et al. (2009) & 1187 & Schaupp et al. (2010) & 260 \\
\hline $\begin{array}{l}\text { Abu-Shanab and Pearson } \\
(2009)\end{array}$ & 878 & Laumer et al. (2010) & 255 \\
\hline Tsai (2009) & 759 & Zhou et al. (2010) & 250 \\
\hline Al-Gahtani et al. (2007) & 722 & Wang and Shih (2009) & 244 \\
\hline Jong and Wang (2009) & 606 & Hung et al. (2007) & 233 \\
\hline Chiu et al. (2010) & 412 & Sapio et al. (2010) & 181 \\
\hline Curtis et al. (2010) & 409 & Chang et al. (2007) & 140 \\
\hline Duyck et al. (2010) & 362 & Luo et al. (2010) & 122 \\
\hline $\begin{array}{l}\text { Aggelidis and Chatzoglou } \\
\text { (2009) }\end{array}$ & 341 & Gupta et al. (2008) & 102 \\
\hline Lin and Anol (2008) & 317 & van Biljon and Kotze (2008) & 57 \\
\hline Ye et al. (2008) & 306 & Alapetite et al. (2009) & 39 \\
\hline Shin (2009) & 296 & Huser et al. (2010) & 18 \\
\hline Chiu and Wang (2008) & 286 & & \\
\hline
\end{tabular}

\section{Relationships between UTAUT Constructs}

Table 4 represents the relationships between UTAUT constructs in terms of significant, non-significant, and not applicable categories. The category is specified as not applicable when the relationship between the constructs are not talked off at all may be because of the obvious reason of the study being qualitative or partially discussing the correlation where the relationship in question is not taken into consideration in that particular study. A number of studies have fallen in the 'not applicable' category 
because correlations between the constructs were not specified in such studies. Moreover, there is relatively a very few number of relationships categorised within nonsignificant category. Performance expectancy shows the highest number of significant relations with behavioral intention, followed by social influence, effort expectancy, and facilitating conditions.

Although relatively a larger numbers of studies have shown significant impacts of facilitating conditions on usage (as per the original model of UTAUT), there are still some studies which have analyzed impact of facilitating conditions on behavioral intention as well. Moreover, only eight out of 43 studies have shown the relationship between behavioral intention and usage.

Table 4. Relationships with UTAUT constructs (approach adapted from Lee et al. 2003)

\begin{tabular}{|c|c|c|c|c|c|c|}
\hline Relationship Type & $P E \gg B I$ & $\mathrm{EE} \gg \mathrm{BI}$ & $\mathrm{SI} \rightarrow \mathrm{BI}$ & $\mathrm{FC} \mapsto \mathrm{BI}$ & $\mathrm{FC} \rightarrow \mathrm{U}$ & $\mathrm{BI} \gg \mathrm{U}$ \\
\hline Significant & 25 & 19 & 22 & 9 & 14 & 8 \\
\hline Non-Significant & 0 & 5 & 3 & 2 & 2 & 0 \\
\hline Not Applicable & 18 & 19 & 18 & 32 & 27 & 35 \\
\hline Total & 43 & 43 & 43 & 43 & 43 & 43 \\
\hline
\end{tabular}

\section{Reliability of UTAUT Constructs}

Table 5 lists Chronbach's alpha $(\alpha)$ values for indicating reliability of UTAUT constructs across all such studies (18 studies) which have used this theory. Two of the studies have got more than one set of reliabilities because they have been applied to two different set of samples. The remaining nine studies (Alapetite et al. 2009; Duyck et al. 2010; Hung et al. 2007; Jong and Wang 2009; Lin and Anol 2008; Sapio et al. 2010; Shin 2009; Tsai 2009; van Biljon and Kotze 2008) did not provide Chronbach's alpha $(\alpha)$ values for any of its constructs. As per Santos (1999), Chronbach's $(\alpha)$ determines the internal uniformity or average correlation of items in a survey mechanism to measure its reliability. Alpha coefficient varies in the value from zero to one and may be employed to explain the reliability of factors obtained from dichotomous and/or multi-point designed opinion or dimension. The higher the value, the more trustworthy the created dimension is (Santos 1999). Nunnaly (1978) pointed out 0.7 to be a standard reliability coefficient. So, the average reliability for each construct more than 0.7 (as illustrated in table 5) indicates that all of them are falling under the acceptable reliability levels.

\section{UTAUT Correlations}

Figure 1 shows the original UTAUT theory with all its key constructs and their corresponding relationships. The combined correlation of the constructs has been shown in the figure with respect to the individual -values of the constructs. This combined effect of correlation has been calculated using the comprehensive meta-analysis software. 
Table 5. UTAUT constructs with reliabilities [ ${ }^{* N S}=$ Non-Significant] (adapted from King and He 2006)

\begin{tabular}{|l|l|l|l|l|l|l|}
\hline Reference & PE & EE & SI & FC & BI & U \\
\hline Abu-Shanab and Pearson (2009) & 0.929 & 0.905 & 0.821 & 0.0825 & 0.895 & ------- \\
\hline Aggelidis and Chatzoglou (2009) & ------ & ------ & ------ & 0.890 & ------ & ------- \\
\hline Al-Gahtani et al. (2007) & 0.900 & 0.900 & 0.950 & 0.770 & 0.760 & 0.850 \\
\hline Chang et al. (2007) & 0.940 & 0.950 & 0.870 & 0.950 & 0.930 & ------- \\
\hline Chiu and Wang (2008) & 0.850 & 0.890 & 0.890 & 0.820 & 0.940 & ------- \\
\hline Chiu et al. (2010) & ------ & ------ & ------ & ------ & 0.970 & ------ \\
\hline Curtis et al. (2010) & 0.840 & 0.870 & 0.890 & 0.720 & 0.960 & ------- \\
\hline Gupta et al. (2008) & 0.814 & 0.812 & 0.812 & 0.809 & 0.839 & ------- \\
\hline Huser et al. (2010) & 0.871 & 0.849 & ------ & ------- & 0.752 & ------- \\
\hline Kijsanayotin et al. (2009) & 0.930 & 0.930 & 0.890 & 0.900 & 0.970 & ------- \\
\hline Laumer et al. (2010) & 0.736 & 0.795 & ------ & 0.787 & 0.870 & ------- \\
\cline { 2 - 8 } & 0.707 & 0.842 & ------ & 0.587 & 0.883 & ------- \\
\hline Luo et al. (2010) & 0.890 & ------- & ------ & ------- & 0.890 & ------- \\
\hline Nov and Ye (2009) & 0.880 & 0.870 & ------- & ------- & 0.960 & ------- \\
\hline Schaupp et al. (2010) & 0.740 & 0.830 & 0.800 & 0.740 & ------- & 0.910 \\
\hline van Dijk et al. (2008) & 0.750 & 0.830 & 0.150 & -------- & ------- & ------ \\
\cline { 2 - 7 } & $* N S$ & ------- & ------ & ------- & ------- & ------ \\
\hline Wang and Shih (2009) & 0.921 & 0.916 & 0.939 & 0.819 & 0.905 & 0.863 \\
\hline Ye et al. (2008) & ------- & ------- & 0.870 & ------- & ------- & ------- \\
\hline Zhou et al. (2010) & 0.866 & 0.864 & 0.846 & 0.833 & -------- & 0.857 \\
\hline Number of Studies & 17 & 15 & 12 & 13 & 14 & 4 \\
\hline Average Reliability & & & & & & \\
\hline
\end{tabular}

The inputs given to the application for each construct were their individual $\beta$ values and sample size from the specific studies. The combined zero-order correlations for each pair of constructs indicate the significant relationship between them. The R2-value for BI and Usage has been calculated taking the average of R2-values of all the studies and found to be significant as well. Hence, the general concept of the relationship between the constructs is consistent with the original theory of UTAUT (Venkatesh et al. 2003).

Table 6 shows the correlation results for the five relationships for all its constructs (King and He 2006) calculated through comprehensive meta-analysis software. The result shows that PE-BI and BI-U are relatively strongly correlated than the other relationships. The p-values across all the relationships indicate that the correlations between constructs are significant and hence consistent with the original theory of 


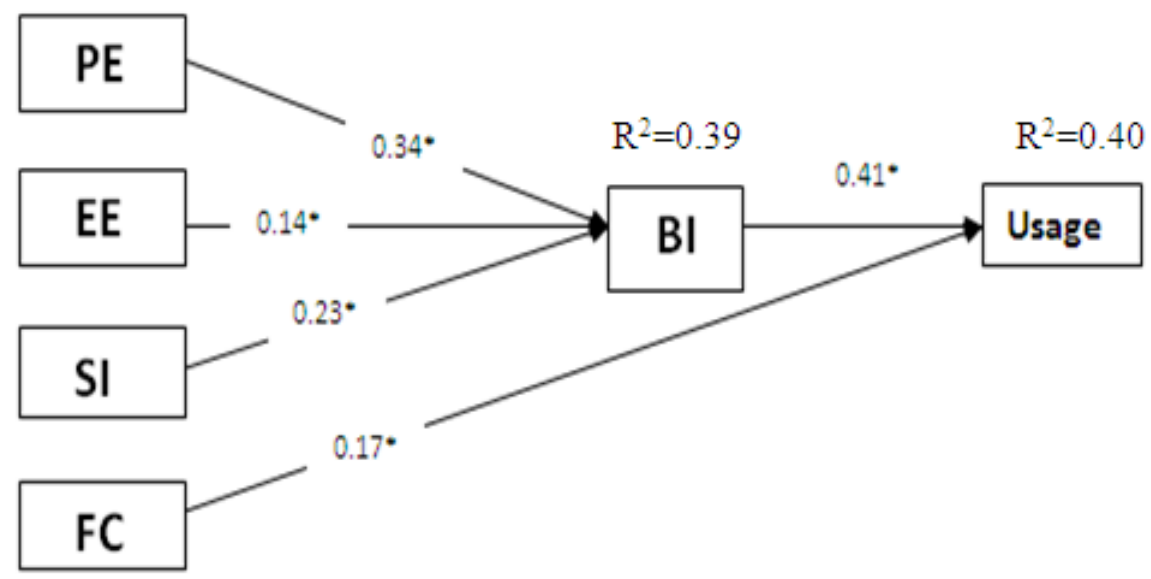

Fig. 1. UTAUT Constructs Combined Correlation with ${ }^{*} \mathrm{p}<0.05$ (model adapted from Venkatesh et al. 2003)

Table 6. Summary of Zero-Order correlations between UTAUT constructs (approach adapted from King and He 2006; Source: Comprehensive Meta-Analysis Software ${ }^{1}$ )

\begin{tabular}{|l|l|l|l|l|l|}
\hline Statistical Measurement & PE $\rightarrow$ BI & EE $\rightarrow$ BI & SI $\rightarrow$ BI & FC $\rightarrow$ U & BI $\rightarrow$ U \\
\hline Number of Studies & 8 & 8 & 10 & 8 & 3 \\
\hline Total Sample Size & 4170 & 4170 & 4453 & 1846 & 1990 \\
\hline Average $(\beta)$ & 0.343 & 0.140 & 0.231 & 0.165 & 0.405 \\
\hline Z-value & 21.699 & 2.201 & 4.945 & 7.103 & 4.097 \\
\hline$p$ (Effect Size) & 0.000 & 0.028 & 0.000 & 0.000 & 0.000 \\
\hline $95 \%$ Low $(\beta)$ & 0.231 & 0.015 & 0.141 & 0.120 & 0.221 \\
\hline $95 \%$ High $(\beta)$ & 0.446 & 0.261 & 0.317 & 0.209 & 0.562 \\
\hline
\end{tabular}

UTAUT. The 95\% confidence interval also supports the correlation values and likelihood of these values to fall in the given interval.

\subsection{Major Limitations of Studies That Have Utilized UTAUT}

Based on some of the common limitations encountered frequently across most of the studies, Table 7 has categorized limitations from individual studies into nine broader categories. Out of 43 studies, there are nine such papers which have not listed any limitations and Table 7 has listed them in a separate category called 'No Limitations Specified'. A considerable number of the studies have mentioned single IS, single subject, or cross-sectional studies as their major limitations. However, there are some studies which have referenced their limitations as: small number of samples, no application of actual usage, self-selection bias, and specialized single task difficult to generalize.

\footnotetext{
${ }^{1}$ Comprehensive Meta-Analysis Software: http://www.meta-analysis.com
} 
Table 7. Summary of limitations of UTAUT studies (approach adapted from Lee et al. 2003)

\begin{tabular}{|l|l|l|l|}
\hline Limitation & Papers (\#) & Explanation & Examples \\
\hline $\begin{array}{l}\text { Self-Reported } \\
\text { Usage }\end{array}$ & 4 & $\begin{array}{l}\text { Does not assess the actual } \\
\text { usage }\end{array}$ & Hung et al. (2007) \\
\hline Single IS & 8 & $\begin{array}{l}\text { Only use a single IS for } \\
\text { research }\end{array}$ & Chang et al. (2007) \\
\hline Student Samples & 1 & $\begin{array}{l}\text { Not appropriate for working } \\
\text { situation }\end{array}$ & Tsai (2009) \\
\hline Single Subject & 12 & $\begin{array}{l}\text { Only one community, } \\
\text { organization, culture or } \\
\text { country }\end{array}$ & Li (2010) \\
\hline $\begin{array}{l}\text { Cross Sectional } \\
\text { Study }\end{array}$ & 5 & $\begin{array}{l}\text { Measured at only one point } \\
\text { of time }\end{array}$ & Chiu et al. (2010) \\
\hline $\begin{array}{l}\text { Measurement } \\
\text { Problems }\end{array}$ & 1 & $\begin{array}{l}\text { Conclusion from data } \\
\text { analysis is difficult }\end{array}$ & Ye et al. (2008) \\
\hline Single Task & 3 & $\begin{array}{l}\text { Difficult to generalize the } \\
\text { result }\end{array}$ & $\begin{array}{l}\text { Wang and Shih } \\
\text { (2009) }\end{array}$ \\
\hline Others & 20 & $\begin{array}{l}\text { Small sample size, } \\
\text { self-selection bias, little } \\
\text { reflection on cultural } \\
\text { difference, short exposure } \\
\text { time to adopt new IS }\end{array}$ & $\begin{array}{l}\text { Schaupp et al. } \\
\text { (2010) }\end{array}$ \\
\hline $\begin{array}{l}\text { No Limitations } \\
\text { Specified }\end{array}$ & $\begin{array}{l}\text { Limitations not mentioned } \\
\text { in the studies }\end{array}$ & Curtis et al. (2010) \\
\hline
\end{tabular}

\section{Discussions}

The findings regarding the relationships between the constructs of UTAUT in Table 8 signify that most of the relationships exist between the constructs are consistently significant. These findings are in accordance with the findings of Venkatesh et al. (2003) in the original paper of UTAUT. However, there are still few relationships which are non-significant in nature and require further attention. Moreover, the relationship between FC and BI needs a further research consideration as most of the studies find this relationship as significant which is in disparity with original composition of the UTAUT (Venkatesh et al. 2003).

But, the findings of the combined effect of the overall relationship between the constructs demonstrated in Table 6 and Figure 2 measured through the meta-analysis software were found to be positive and significant. The comparison of construct correlations from the original theory and the combined effect is presented in Figure 2 below.

The comparison of the correlation values between the constructs from the original theory and the combined effect shows that the direct effects of PE and the direct effects and interaction terms from EE, SI, FC, and BI have got the larger values in original model than the model obtained from the meta-analysis. Although, all relationships appear to be significant in meta-analysis, a lower correlation coefficient $(\beta)$ suggests less consistent performance of UTAUT in various contexts. This may be due to relatively less number of studies used in for the meta-analysis and the absence of moderators in majority of studies that have utilized the UTAUT model. Any future 


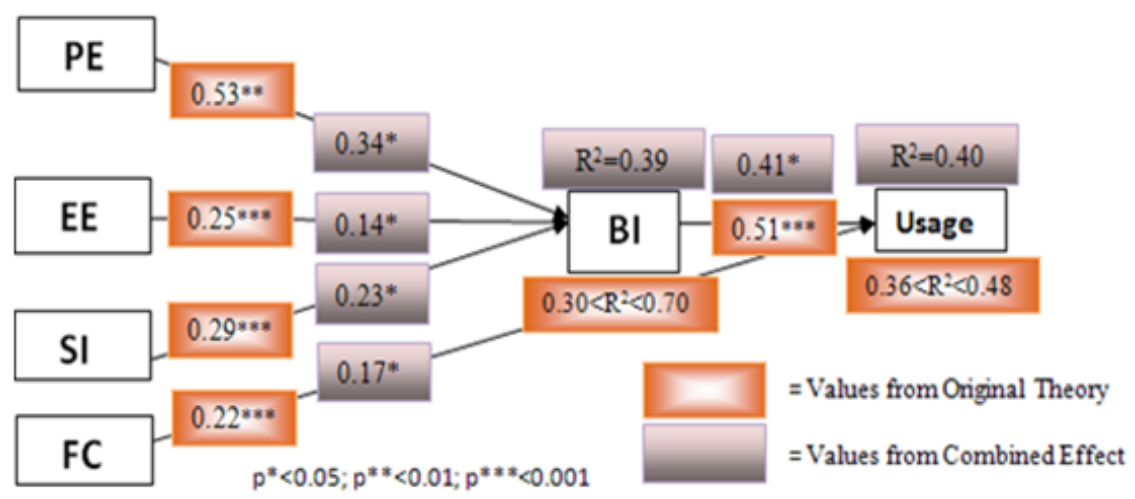

Fig. 2. Construct correlations and R2 from original theory and combined effect (Model adapted from Venkatesh et al. 2003; Data Source: Venkatesh et al. 2003; Comprehensive Meta-Analysis Software)

research wishes to apply UTAUT should apply it in its original form that means effect of moderating variables must not be excluded from the model.

The combined $\mathrm{R}^{2}$-values are computed as an average of all the studies used for meta- analysis as the comprehensive meta-analysis tool does not provide the option for such input and it is found that the $\mathrm{R}^{2}$-values for both $\mathrm{BI}$ and $\mathrm{U}$ fall between the original theory's (Venkatesh et al. 2003) value range of 'direct effects only' and 'direct effects and interaction terms values' and hence acceptable.

The findings for the average combined reliability through Chronbach's $(\alpha)$ in Table 5 represent that all the constructs except FC (with acceptable reliability of 0.735 ) are greater than or equal to 0.8 , and therefore, highly reliable and these findings are similar to TAM meta-analysis findings measured by King and He (2006) across the various studies where they also considered the reliability of 0.8 as highly reliable. The findings regarding the limitations for the studies specified in Table 7 are in line with one used in Lee et al. (2003) for TAM studies' limitations and open up a further scope of future research in those areas. Most of the studies are analyzed either along single IS, single subject, or single task category where they are applicable only to a specific area of research. Hence, a serious research agenda is to make them compatible with the generic scenarios. Although most of the studies are cross-sectional in nature, it becomes a potential limitation for them sometimes as they do not provide a clear picture of adoption of the technology. Lee et al. (2003) argue that users' intent and opinion may change over the period of time and hence it is required to assess the adoption behavior at various points over longer period of time (Lee et al. 2003).

\section{Conclusions}

- The following significant points emerged from the findings and discussions presented in this study are:

- A number of empirical studies that utilized UTAUT were based on relatively very small sample size. 
- There is an increasing trend of using external variables and external theories together with the UTAUT.

- Relationships between external variables along with UTAUT constructs and behavioral intention were generally reported as significant or mixed significant.

- Reliability of UTAUT's survey instrument was found consistent in all citations that have utilized it.

- The overall effect of zero-order correlations between independent and dependent constructs of UTAUT was found significant.

The findings from this study also have relevance for technology adoption and diffusion research. The refined model of UTAUT based on meta-analysis that presented within this report may contribute to the area of IS/IT adoption and diffusion research as it raises many vital points related to the original model. For example, those studies that are utilizing UTAUT model generally ignore the effect of moderating variables which might be distorting the actual performance of the theory. It also highlights issue of integrating external variables without giving strong and logical justifications, for example, some studies have utilized both usefulness and performance expectancy and others have utilized both effort expectancy and ease of use. These constructs are essentially similar in nature and should not be employed in same study to avoid repetitions and redundancy.

\subsection{Limitations and Further Research Directions}

The first limitation is that some studies could not be taken into consideration because of the lack of privileged access rights for some journals such as European Journal of Information Systems, and Journal of Information Technology. The future researchers can look for the access more such UTAUT related studies in order to more accurately explore the meta-analysis. Secondly, the study does not take into consideration the analysis of moderating variables and their impacts on the constructs. The researchers can more elaborately analyze the effect of moderators such as age, gender, experience, and voluntariness of use on the relationships of the constructs to get more effective outcome. Thirdly, the combined $\mathrm{R}^{2}$-value for BI and $\mathrm{U}$ has not been computed using the meta-analysis tool as they do not have any such option for generating the combined effect for the same and hence represented just by taking the average of individual R2-values. The future researchers need to explore some more appropriate method to compute the combined $\mathrm{R}^{2}$-value through some specific software tool or relevant statistical measurements. Fourthly, the study has not considered the structural relationship between UTAUT constructs where majority of researchers have been more fascinated about it as it helps them explicate individuals' adoption of new technologies, than in the zero-order correlations (King and He 2006). This research could have been made more generalized by incorporating the structural relationships between the constructs where most of the researchers are more interested about. Lastly, this study has not considered qualitative studies as a potential candidate for metaanalysis as King and He (2006) have done in the meta-analysis of TAM studies. The future research can also explore this kind of meta-analysis to be included along with quantitative one. 


\section{References}

Abu-Shanab, E., Pearson, M.: Internet Banking in Jordan: An Arabic Instrument Validation Process. International Arab Journal of Information Technology 6(3), 235-244 (2009)

Aggelidis, V.P., Chatzoglou, P.D.: Using a modified technology acceptance model in hospitals. International Journal of Medical Informatics 78(2), 115-126 (2009)

Alapetite, A., Andersen, H.B., Hertzum, M.: Acceptance of speech recognition by physicians: A survey of expectations, experiences, and social influence. International Journal of HumanComputer Studies 67(1), 6-49 (2009)

Al-Gahtani, S.S., Hubona, G.S., Wang, J.: Information technology (IT) in Saudi Arabia: Culture and the acceptance and use of IT. Information \& Management 44(8), 681-691 (2007)

Baron, S., Patterson, A., Harris, K.: Beyond technology acceptance: understanding consumer practice. International Journal of Service Industry Management 17(2), 111-135 (2006)

Borenstein, M.: Effect Sizes for Continuous Data. In: Cooper, H., Hedges, L.V., Valentine, J.C. (eds.) The Handbook of Research Synthesis and Meta-Analysis. Russell Sage Foundation, New York (2009)

Chang, I.C., Hwang, H.G., Hung, W.F., Li, Y.C.: Physicians' acceptance of pharmacokineticsbased clinical decision support systems. Expert Systems with Applications 33(2), 296-303 (2007)

Chiu, C.M., Wang, E.T.G.: Understanding Web-based learning continuance intention: The role of subjective task value. Information \& Management 45(3), 194-201 (2008)

Chiu, C.M., Huang, H.Y., Yen, C.H.: Antecedents of trust in online auctions. Electronic Commerce Research and Applications 9(2), 148-159 (2010)

Curtis, L., Edwards, C., Fraser, K.L., Gudelsky, S., Holmquist, J., Thornton, K.: Adoption of social media for public relations by non-profit organizations. Public Relations Review 36(1), 90-92 (2010)

Dadayan, L., Ferro, E.: When technology meets the mind: A comparative study of the technology acceptance model. In: Wimmer, M.A., Traunmüller, R., Grönlund, Å., Andersen, K.V. (eds.) EGOV 2005. LNCS, vol. 3591, pp. 137-144. Springer, Heidelberg (2005)

Deng, X., Doll, W.J., Hendrickson, A.R., Scazzero, J.A.: A multi-group analysis of structural invariance: an illustration using technology acceptance model. Information \& Management 42(5), 745-759 (2005)

Duyck, P., Pynoo, B., Devolder, P., Voet, T., Adang, L., Ovaere, D.: Monitoring the PACS Implementation Process in Large University Hospital-Discrepancies between Radiologists and Physicians. Journal of Digital Imaging 23(1), 73-80 (2010)

Field, A.P.: Meta-analysis of correlation coefficients: a Monte Carlo comparison of fixed- and random-effects methods. Psychological Methods 6(2), 161-180 (2001)

Gupta, B., Dasgupta, S., Gupta, A.: Adoption of ICT in a government organization in a developing country: An empirical study. Journal of Strategic Information Systems 17(2), 140-154 (2008)

Hausenblas, H.A., Carron, A.V., Mack, D.V.: Application of the theories of reasoned action and planned behavior to exercise behavior: A meta-analysis. Journal of Sport \& Exercise Psychology 19(1), 36-51 (1997)

He, D.H., Lu, Y.B., Alfred, U.: An integrated framework for mobile business acceptance. Alfred Univ., Alfred (2007)

Hung, Y.H., Wang, Y.S., Chou, S.C.T.: User Acceptance of E-Government Services. Natl Sun Yat-Sen Univ., Kaohsiung (2007)

Huser, V., Narus, S.P., Rocha, R.A.: Evaluation of a flowchart-based EHR query system: A case study of RetroGuide. Journal of Biomedical Informatics 43(1), 41-50 (2010) 
Jong, D., Wang, T.S.: Student Acceptance of Web-based Learning System. Acad. Publ., Oulu (2009)

Kijsanayotin, B., Pannarunothai, S., Speedie, S.M.: Factors influencing health information technology adoption in Thailand's community health centers: Applying the UTAUT model. International Journal of Medical Informatics 78(6), 404-416 (2009)

King, W.R., He, J.: A meta-analysis of the technology acceptance model. Information \& Management 43, 740-755 (2006)

Laumer, S., Eckhardt, A., Trunk, N.: Do as your parents say?-Analyzing IT adoption influencing factors for full and under age applicants. Information Systems Frontiers 12(2), 169-183 (2010)

Lee, Y., Kozar, K.A., Larsen, K.R.T.: The Technology Acceptance Model: Past, Present, and Future. Communications of the Association for Information System 12, 752-780 (2003)

Legris, P., Ingham, J., Collerette, P.: Why do people use information technology? A critical review of the technology acceptance model. Information \& Management 40(3), 191-204 (2003)

Li, W.: Virtual knowledge sharing in a cross-cultural context. Journal of Knowledge Management 14(1), 38-50 (2010)

Lin, C.P., Anol, B.: Learning online social support: An investigation of network information technology based on UTAUT. Cyber Psychology \& Behavior 11(3), 268-272 (2008)

Loo, W.H., Yeow, P.H.P., Chong, S.C.: User acceptance of Malaysian government multipurpose smartcard applications. Government Information Quarterly 26(2), 358-367 (2009)

Luo, X., Li, H., Zhang, J., Shim, J.P.: Examining multi-dimensional trust and multi-faceted risk in initial acceptance of emerging technologies: An empirical study of mobile banking services. Decision Support System 49(2), 222-234 (2010)

Ma, Q., Liu, L.: The technology acceptance model: a meta-analysis of empirical findings. Journal of Organizational and End User Computing 16(1), 59-72 (2004)

Nov, O., Ye, C.: Resistance to Change and the Adoption of Digital Libraries: An Integrative Model. Journal of the American Society for Information Science and Technology 60(8), 1702-1708 (2009)

Nunnaly, J.: Psychometric theory. McGraw-Hill, New York (1978)

Santos, J.R.A.: Chronbach's Alpha: A Tool for Assessing the Reliability of Scales. Journal of Extension 37(2), 1-5 (1999)

Sapio, B., Turk, T., Cornacchia, M., Papa, F., Nicolo, E., Livi, S.: Building scenarios of digital television adoption: a pilot study. Technology Analysis \& Strategic Management 22(1), 43 $63(2010)$

Schaupp, L.C., Carter, L., McBride, M.E.: E-file adoption: A study of US taxpayers' intentions. Computers in Human Behavior 26(4), 636-644 (2010)

Sheeran, P., Taylor, S.: Predicting Intentions to Use Condoms: A Meta-Analysis and Comparison of the Theories of Reasoned Action and Planned Behavior. Journal of Applied Social Psychology 29(8), 1624-1675 (1999)

Shin, D.H.: Towards an understanding of the consumer acceptance of mobile wallet. Computers in Human Behavior 25(6), 1343-1354 (2009)

Tsai, Y.H., Lin, C.P., Chiu, C.K., Joe, S.W.: Understanding learning behavior using location and prior performance as moderators. Social Science Journal 46(4), 787-799 (2009)

van Biljon, J., Kotze, P.: Cultural Factors in a Mobile Phone Adoption and Usage Model. Journal of Universal Computer Science 14(16), 2650-2679 (2008) 
van Biljon, J., Renaud, K.: A Qualitative Study of the Applicability of Technology Acceptance Models to Senior Mobile Phone Users. In: Song, I.-Y., Piattini, M., Chen, Y.-P.P., Hartmann, S., Grandi, F., Trujillo, J., Opdahl, A.L., Ferri, F., Grifoni, P., Caschera, M.C., Rolland, C., Woo, C., Salinesi, C., Zimányi, E., Claramunt, C., Frasincar, F., Houben, G.-J., Thiran, P. (eds.) ER Workshops 2008. LNCS, vol. 5232, pp. 228-237. Springer, Heidelberg (2008)

van Dijk, J., Peters, O., Ebbers, W.: Explaining the acceptance and use of government Internet services: A multivariate analysis of 2006 survey data in the Netherlands. Government Information Quarterly 25(3), 379-399 (2008)

Venkatesh, V., Morris, M.G., Davis, G.B., Davis, F.D.: User acceptance of information technology: Toward a unified view. MIS Quarterly 27(3), 425-478 (2003)

Wang, Y.S., Shih, Y.W.: Why do people use information kiosks? A validation of the Unified Theory of Acceptance and Use of Technology. Government Information Quarterly 26(1), 158-165 (2009)

Ye, C., Seo, D., Desouza, K.C., Sangareddy, S.P., Jha, S.: Influences of IT Substitutes and User Experience on Post-Adoption User Switching: An Empirical Investigation. Journal of the American Society for Information Science and Technology 59(13), 2115-2132 (2008)

YenYuen, Y., Yeow, P.H.P.: User Acceptance of Internet Banking Service in Malaysia. In: Cordeiro, J., Hammoudi, S., Filipe, J. (eds.) Web Information Systems and Technologies, vol. 18, pp. 295-306. Springer, Berlin (2009)

Yeow, P.H.P., Yuen, Y.Y., Tong, D.Y.K., Lim, N.: User acceptance of Online Banking Service in Australia. Int. Business Information Management Assoc-Ibima, Norristown (2008)

Zhou, T., Lu, Y.B., Wang, B.: Integrating TTF and UTAUT to explain mobile banking user adoption. Computers in Human Behavior 26(4), 760-767 (2010) 